\title{
Hippocampus and amygdala: An insight-related network involved in metaphorical solution to mental distress problem
}

\author{
Fei $\mathrm{Yu}^{1,2} \cdot$ Jianxin Zhang ${ }^{1,2} \cdot$ Jin Fan ${ }^{3} \cdot$ Jing Luo ${ }^{4} \cdot$ Wencai Zhang ${ }^{1,2}$ \\ Published online: 26 February 2019 \\ (C) The Psychonomic Society, Inc. 2019
}

\begin{abstract}
This study was designed to determine whether metaphorical solutions to mental distress problems result in an insightful mental experience and activate the hippocampus and amygdala: areas associated with insight. We recruited 22 healthy university students. Trials presented 75 micro-counseling scenarios while event-related functional magnetic resonance imaging (fMRI) was applied to detect neural responses. Each scenario included a mental distress problem and one of the following solution types: metaphorical, literal, or problem-restatement. The results revealed that, compared with literal solutions or problem-restatement solutions, metaphorical solutions activated two neural networks: one associated with basic metaphorical language processing (i.e., the left inferior frontal gyrus and middle and superior temporal gyri), and a specific network associated with insightful problem solving (i.e., the bilateral hippocampus, amygdala, and fusiform gyrus). Our findings indicate that the use of metaphorical solutions to mental distress problems reliably produces salient neural activities for insight.
\end{abstract}

Keywords Metaphor $\cdot$ Insight $\cdot$ Novelty $\cdot$ Hippocampus $\cdot$ Amygdala $\cdot$ Micro-counseling scenario

Metaphor plays an important role in the transmission of new schemata of thought during cognitive therapy (Muran \& Digiuseppe, 1990). In the field of psycholinguistics, neural correlates of metaphor comprehension have been widely investigated over the past decade (Benedek et al., 2014; Bohrn, Altmann, \& Jacobs, 2012; Rapp, Leube, Erb, Grodd, \& Kircher, 2004; Rapp, Mutschler, \& Erb, 2012; Yang, 2014). However, the underlying neural mechanisms of metaphor in the context of cognitive therapy remain unknown.

Fei Yu and Jianxin Zhang contributed equally to this work.

Wencai Zhang

zhangwc@psych.ac.cn

1 Key Laboratory of Mental Health, Institute of Psychology, Chinese Academy of Sciences, 16 LinCui Road, Chaoyang District,

Beijing 100101, People's Republic of China

2 Department of Psychology, University of Chinese Academy of Sciences, 19 A Yuquan Road, Shijingshan District, Beijing 100049, People's Republic of China

3 Department of Psychology, Queens College, The City University of New York, 65-30 Kissena Blvd., Flushing, NY 11367, USA

4 Beijing Key Laboratory of Learning and Cognition, Department of Psychology, Capital Normal University, Beijing 100048, People's Republic of China
Therapeutic metaphor is believed to have potential in producing therapeutic insight. Conceptual metaphor theory (CMT) posits that conceptual metaphor is a cognitive tool that people use to represent an abstract target concept in terms of a superficially unrelated, typically more concrete source concept (Lakoff \& Johnson, 1980). According to MacCormac (1985), metaphor is "the creative cognitive process of activating widely separated areas of long-term memory and of combining normally unassociated concepts." First, the use of metaphor in cognitive therapy helps clients to gain insight and make changes in their lives (Kok, Lim, \& Low, 2011; Pollio, Barlow, Fine, \& Pollio, 1977). Therapists of various theoretical orientations agree that insight is a salient characteristic of a "good therapist" (Novotney, 2013) and insight is also termed cognitive restructuring in cognitive therapy (Grosse Holtforth et al., 2007). The use of metaphor in psychotherapy can introduce a different way of perceiving and organizing the world, making it easier to breach the epistemological gap between old and new knowledge (Muran \& Digiuseppe, 1990). Because metaphor involves both imagistic and verbal processes, it can further facilitate the acquisition, retention, and recall of new paradigms (Muran \& Digiuseppe, 1990; Paivio, 1986). Prior researches have indicated that novel metaphoric language constituted the contents of specific therapeutic insights (Barlow, Pollio, \& Fine, 1977; Elliott et al., 1994), and clients rated therapy sessions in which they recalled their therapists' 
intentional use of metaphor as more helpful than other sessions (Martin, Cummings, \& Hallberg, 1992). Additionally, empirical evidence has demonstrated that metaphor is effective in ameliorating irrational beliefs (Komasi, Saeidi, Zakiei, Amiri, \& Soltani, 2016), as well as in changing catastrophizing and pain biology knowledge (Gallagher, Mcauley, \& Moseley, 2013).

Second, in the other domains, the use of metaphor could foster insight process and facilitate problem solving (Keefer \& Landau, 2016; Slepian, Weisbuch, Rutchick, Newman, \& Ambady, 2010). The investigators found that the use of prototypical metaphor in solving scientific innovation problems facilitates insight process (Yang et al., 2016). Archimedes cracking the mystery of the crown is a famous example; he suddenly realized that he could use the water displacement to work out the volume and density of the king's crown and shouted "Eureka!" Insightful problem solving is one classical subfield of creativity (Abraham \& Windmann, 2007), and metaphor is considered as a creative language expression due to its properties of novelty and imagery (Lakoff \& Johnson, 1980). Metaphor also is used to investigate creativity. For example, Benedek et al. (2014) used metaphor to investigate the neural correlates of creativity production by generating novel metaphors or literal synonyms to complete sentences. In a word, therapeutic metaphor has distinct potentials in producing insight for mental distress problems due to its cognitive superiority in conceptual transference and creative characteristics.

However, the neural mechanisms of therapeutic metaphor and its correlation with insight experience have yet to be elucidated. The difficulty in collecting relevant data may explain the lack: a well-designed study would have to record brain activity in response to metaphor both in real time and in the context of psychotherapy. Moreover, the latter requirement would have to repeatedly present therapeutic metaphors for the valid isolation and measurement of related neural activity.

Micro-counseling scenarios have been used repeatedly to present therapeutic metaphor in prior research $(\mathrm{Hu}$, Zhang, Zhang, Yu, \& Zhang, 2018; Jiang, Yu, Zhang, \& Zhang, 2016; Yu, Zhang, Zhang, Zhang, \& Luo, 2016). In this context, "maladaptive" and "adaptive" thinking were reduced to "problems" and "solutions," respectively. Participants of such studies read a description of a mental distress problem (e.g., "I feel extremely frustrated, because I am beginning a major that I dislike") followed by one of three randomly matched solutions: metaphorical, literal, or problem-restatement. The first type reinterprets the functional aspects involved in a problem by applying a metaphor, including various figures of speech; for example, "Success in life is not holding good cards but playing bad cards well." The literal solution reinterprets the functional aspects of an issue by providing a plain, soothing expression in literal language: "success mainly depends on effort, it is important to do a good job now." The problem- restatement solution rephrases the original problem using literal wording: "your current major is not your favorite, you lack confidence in your future." Researchers found that the metaphorical solutions yielded the greatest degree of insightfulness and novelty for both psychotherapists and students, followed respectively by literal and problemrestatement solutions (Yu et al., 2016). The problem-solution scenarios in the micro-counseling context referenced the riddle paradigm, which was used in a neuroimaging study on insight to observe brain activities of insight processing (Luo \& Niki, 2003). The investigators asked participants to read a riddle and then provided them with the solution. The therapeutic metaphor in the micro-counseling scenario thus meets our criteria for a method to detect neural mechanisms of therapeutic metaphor: (a) capturing online multiple events of therapeutic metaphor in one functional magnetic resonance imaging (fMRI) scanning session, and (b) ecologically valid stimuli that resemble an actual psychotherapy scenario.

We further sought to identify the specific brain regions activated by therapeutic metaphor, because empirical evidence has demonstrated that therapeutic metaphor is more effective in alleviating mental distress (Gallagher et al., 2013; Komasi et al., 2016), and the insightfulness experiences produced by therapeutic metaphor in the micro-counseling scenarios could predict the reduction of negative affect after the intervention (Hu et al., 2018). The neuroimaging studies demonstrated that metaphor comprehension induced different activities than did literal sentences; metaphor significantly increased signal changes in the left inferior frontal gyrus (IFG; Brodmann area (BA) 45/47), as well as in the left inferior and middle temporal gyri (ITG and MTG, respectively) (Rapp et al., 2004; Bohrn et al., 2012; Rapp et al., 2012). Moreover, it was found that metaphor or simile utterances in a naturally evolving, continuous, and coherent story rather than isolated or single sentences resulted in significantly higher levels of activation in the left IFG, MTG, and superior temporal gyrus (STG) (Eviatar \& Just, 2006; Nagels et al., 2013). Prior research also reported that metaphorical solutions to mental distress problems were associated with the experience of insightfulness (Yu et al., 2016). To the best of our knowledge, fMRI technique has not been used to investigate insight-related brain activation induced by therapeutic metaphor. Other domains of insight research, however, have benefitted from numerous neuroimaging studies. One important early neuroimaging study on insight found that receiving the answer to a riddle increased hippocampal activity (Luo \& Niki, 2003). Other research found that the hippocampus and amygdala were both activated by induced or self-generated insight in a perceptual task, as well as in a compound remote-associates task (Huang, Fan, \& Luo, 2015; Kizilirmak, Thuerich, FoltaSchoofs, Schott, \& Richardson-Klavehn, 2016; Ludmer, Dudai, \& Rubin, 2011; Tik et al., 2018; Zhao et al., 2013). The literature on metaphorical language comprehension has featured scant discussion of the hippocampus and amygdala. 
The present study sought to identify neural correlates of therapeutic metaphor in micro-counseling scenarios. We hypothesized that: (a) brain regions associated with basic metaphorical language comprehension, such as the IFG, MTG, and STG, would be involved in the processing of therapeutic metaphor; and (b) that brain regions correlated with the experience of insight but not associated with basic metaphor understanding, such as the hippocampus and amygdala, also would be recruited in the processing of therapeutic metaphor.

\section{Methods}

\section{Participants}

The present study recruited 22 undergraduate and graduate volunteers (12 women, 10 men; age range, 19-27 years; mean $(M)=22.95$; standard deviation $(S D)=2.04)$ from universities in Beijing, China. None of the participants had any medical, neurological, or psychiatric illness. The study was approved by the ethical committee of the Institute of Psychology, Chinese Academy of Sciences and was performed according to the Declaration of Helsinki. All participants gave written, informed consent and received compensation for their participation of the study. Due to excessive head movement during the fMRI scans (see fMRI data analysis below), two participants were removed from the final analyses.

The sample size was calculated with the G*Power 3.1. The effect size of $\mathrm{f}=2.03$ (this $\mathrm{f}$ value was obtained by a convertible calculation of $\eta_{p}^{2}=0.805$ for insightfulness rating) in a previous study using the same paradigm (Yu et al., 2016), and thus 4 observations (i.e. approximately 1.33 participants) were required to detect such effect size with a type I error of 5\% and $80 \%$ power in the one-way repeated-measures ANOVA test. However, we could not determine whether this small sample size was suitable to detect brain activation or not. We assumed an effect as medium as $\mathrm{f}=0.3$ in the present study, 61 observations (i.e. approximately 20.33 participants) were required to detect such effect size with a type I error of 5\% and $80 \%$ power in the one-way repeated-measures ANOVA test. It indicated that the sample size in the present study was appropriate.

\section{Materials}

The experiment consisted of 75 micro-counseling scenarios. Each of these featured of a description of mental distress (the problem) followed by a matched response (the solution). The material database included three types of the latter: a metaphorical solution (MET), which applied figures of speech to reinterpret the functional or emotional reactions present in a situation; a literal solution (LIT), which provided a plain, soothing reinterpretation of the functional or emotional reactions present in a situation in literal language; and a problemrestatement solution (PRO-R), which rephrased the original problem using literal wording. Only one of these three solutions was randomly matched to each problem in the formal experiment. For example, to the problem "I feel extremely frustrated, because I am beginning a major that I dislike," we provided the following: a metaphorical solution, "Success in life is not holding good cards but playing bad cards well"; a literal solution, "success mainly depends on effort, it is important to do a good job now"; and a problemrestatement solution, "your current major is not your favorite, you lack confidence in your future." Several examples were provided in the Table 1. The length of each problem and solution description was limited to 24-30 Chinese characters, including punctuation. There were thus 75 problems to which 25 solutions of each type were randomly assigned for each participant. These scenarios were previously assessed in the study of Yu et al. (2016) by experts in psychology and university students on a nine-point Likert scale. Their findings showed that different levels of insightfulness and novelty

Table 1 Examples of the experimental materials

\begin{tabular}{|c|c|c|c|}
\hline Problems & $\begin{array}{l}\text { Metaphorical } \\
\text { solutions }\end{array}$ & Literal solutions & $\begin{array}{l}\text { Problem- } \\
\text { restatement } \\
\text { solutions }\end{array}$ \\
\hline $\begin{array}{l}\text { I feel extremely } \\
\text { frustrated } \\
\text { because of } \\
\text { beginning a } \\
\text { major I } \\
\text { dislike. }\end{array}$ & $\begin{array}{l}\text { Success in life is } \\
\text { not holding } \\
\text { good cards } \\
\text { but playing } \\
\text { bad cards } \\
\text { well. }\end{array}$ & $\begin{array}{l}\text { Success mainly } \\
\text { depends on } \\
\text { efforts, it is } \\
\text { important to } \\
\text { do a good job } \\
\text { now. }\end{array}$ & $\begin{array}{l}\text { Your current } \\
\text { major is not } \\
\text { your favorite, } \\
\text { you lack } \\
\text { confidence in } \\
\text { the future. }\end{array}$ \\
\hline $\begin{array}{l}\text { I have no } \\
\text { motivation to } \\
\text { do anything } \\
\text { before I get } \\
\text { the result of } \\
\text { an important } \\
\text { exam. }\end{array}$ & $\begin{array}{l}\text { Life is like } \\
\text { riding, you } \\
\text { must keep } \\
\text { moving to } \\
\text { keep your } \\
\text { balance. }\end{array}$ & $\begin{array}{l}\text { Live your life } \\
\text { with your } \\
\text { normal } \\
\text { rhythm, thus } \\
\text { you will not } \\
\text { feel confused. }\end{array}$ & $\begin{array}{l}\text { The test is so } \\
\text { important that } \\
\text { all you can do } \\
\text { is waiting for } \\
\text { the result. }\end{array}$ \\
\hline $\begin{array}{l}\text { I feel angry } \\
\text { when I } \\
\text { persuade } \\
\text { those who } \\
\text { dress } \\
\text { vulgarly, } \\
\text { because they } \\
\text { do not accept } \\
\text { my advice. }\end{array}$ & $\begin{array}{l}\text { The shoe that } \\
\text { fits one } \\
\text { pinches } \\
\text { another; there } \\
\text { is no recipe } \\
\text { for living that } \\
\text { suits all cases. }\end{array}$ & $\begin{array}{l}\text { Everyone has his } \\
\text { own aesthetic } \\
\text { view. You } \\
\text { need not ask } \\
\text { others to } \\
\text { agree with } \\
\text { you }\end{array}$ & $\begin{array}{l}\text { You are very } \\
\text { angry because } \\
\text { others } \\
\text { disagree with } \\
\text { you on } \\
\text { aesthetic } \\
\text { feeling. }\end{array}$ \\
\hline $\begin{array}{l}\text { I feel so sad and } \\
\text { depressed } \\
\text { after broken } \\
\text { up from love, } \\
\text { and cannot } \\
\text { find what } \\
\text { makes me } \\
\text { happy. }\end{array}$ & $\begin{array}{l}\text { If you shed tears } \\
\text { when you } \\
\text { miss the sun, } \\
\text { you also miss } \\
\text { the stars. }\end{array}$ & $\begin{array}{l}\text { Although } \\
\text { broken up, } \\
\text { you have } \\
\text { families and } \\
\text { friend, and } \\
\text { will find they } \\
\text { still love you. }\end{array}$ & $\begin{array}{l}\text { You are so } \\
\text { painful and } \\
\text { unhappy after } \\
\text { broken up, } \\
\text { and have no } \\
\text { spirit to do } \\
\text { anything. }\end{array}$ \\
\hline
\end{tabular}



(Insightfulness: for the expert sample, MET, $M=6.44, S D=$ 1.27 , LIT, $M=5.25, S D=0.74$, PRO-R, $M=3.53, S D=1.43$; for the student sample, MET, $M=6.89, S D=0.91$, LIT, $M=$ 6.31, $S D=1.08$, PRO-R, $M=3.74, S D=1.33$. Novelty: for the expert sample, MET, $M=6.41, S D=1.10$, LIT, $M=3.37$, $S D=1.83$, PRO-R, $M=3.14, S D=1.18$; for the student 1.73, PRO-R, $M=3.38, S D=1.34$ ).

\section{Design and procedure}

The present study used fMRI to detect brain responses induced by metaphorical, literal, and problem-restatement solutions with a within-subjects design. Participants were informed that they would read micro-counseling scenarios, each of which consisted of a problem (i.e., the descriptions of ideas or thoughts the clients may have when encountering negative events or problematic settings) and a corresponding solution (i.e., the descriptions of ideas or thoughts the psychological therapists may provide). They were instructed to imagine vividly the pairings as if they were part of an interactive counseling scenario and to rate the problems and solutions from the viewpoint of the clients. Descriptions of the problems and solutions were presented to participants in the scanner using E-prime software (Version 2, Psychology Software Tools).

To first familiarize participants with the procedure and pace of the task, they completed a training session outside the scanner; this procedure used six scenarios that were not presented in the formal fMRI scan. In the formal scanning phase, 75 scenarios were presented randomly and allocated into 3 blocks. Thus, there were 25 trails in each block. Within each block, three different types of solutions were pseudorandomly organized and solutions from the same category were presented no more than three times in a row to avoid habituation and order effects. Each problem and solution was presented as a complete sentence in a line of white Chinese characters against a black background; it was projected onto a screen visible to the participants through a mirror. As shown in Fig. 1, each trial began with a fixation cross presented in the center of the screen with a random jitter of $1-4 \mathrm{~s}$. The problem was then displayed for $8 \mathrm{~s}$ followed by a second jitter of 1-4 s. The solution was then presented for $8 \mathrm{~s}$, after which the participants were allowed $6 \mathrm{~s}$ to rate the emotional valence of the could be induced by the three types of solutions sample, MET, $M=6.67, S D=1.04$, LIT, $M=5.41, S D=$

solution (i.e., to what extent the solution was emotionally positive) on a nine-point Likert scale; a score of 1 indicated "not at all," whereas a score of 9 corresponded to "very much." After the fMRI scanning (approximately 40 minute for tasks) was completed, in order to know more details about the participants' experiences while reading these microcounseling scenarios, 2 minutes later they were requested to rate the materials again at another quiet laboratory (approximately 40 minutes for tasks). For this second evaluation, participants were instructed to assess the problems in terms of emotional valence and adaptability (i.e., to what extent the solution was functional or helpful in adapting to challenges) and to assess the solutions in terms of emotional valence, adaptability, novelty (i.e., to what extent the solution was distinctive and unexpected), and insightfulness (i.e., to what extent there was a cognitive "click" or new enlightenment that would improve understanding of a problem) on a nine-point Likert scale; 1 indicated "not at all" and 9 indicated "very much," the same as Yu et al. (2016). They were asked to assess the problems and matched solutions based on their present experiences and not to recall the ratings assessed in the fMRI scanner deliberately. The sequence of materials presented was identical to that of the scanning phase.

\section{fMRI data acquisition and analysis}

All scanning was performed with a Siemens Trio 3.0 Tesla MR-scanner using a standard radio frequency head coil. The head was fixed with foam pads during scanning to minimize head movement. A T2*-weighted echo-planar imaging (EPI) sequence based on blood oxygenation level-dependent (BOLD) contrast was acquired with 33 interleaved axial slices to cover the whole brain. The imaging parameters were as follows: thickness $=4.0 \mathrm{~mm}$, repetition time $(\mathrm{TR})=2 \mathrm{~s}$, echo time $(\mathrm{TE})=30 \mathrm{~ms}$, flip angle $(\mathrm{FA})=90^{\circ}$, field of view $(\mathrm{FOV})$ $=192 \times 192 \mathrm{~mm}^{2}$, matrix size $=64 \times 64$ mesh, and voxel size $=3.0 \times 3.0 \times 4.0 \mathrm{~mm}^{3}$. For each participant, a high-resolution T1-weighted 3D magnetization prepared rapid gradient echo pulse (MPRAGE) sequence was acquired for the coregistration and standardization to a template brain (thickness $=1.00 \mathrm{~mm}, \mathrm{TR}=2600 \mathrm{~ms}, \mathrm{TE}=3.02 \mathrm{~ms}, \mathrm{FOV}=256 \times$ $256 \mathrm{~mm}^{2}$, and voxel size $=1.0 \times 1.0 \times 1.0 \mathrm{~mm}^{3}$ ) .

Preprocessing and statistical analyses were performed using Statistical Parametric Mapping (SPM8, http://www.fil.

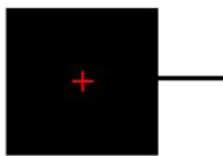

1-4s

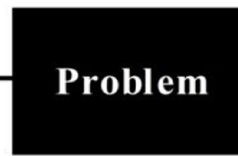

$8 s$

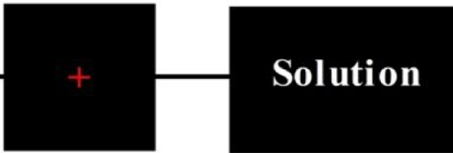

1-4s
Fig. 1 One trial. The participants first read a problem and then a solution. The two were presented for $8 \mathrm{~s}$, and then participants were allowed $6 \mathrm{~s}$ to rate to what extent the solution was emotionally positive

\section{8s}

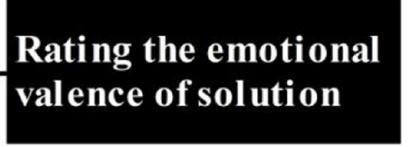

6s on a nine-point Likert scale. There was a jittered fixation cross of 1-4 seconds before each problem and solution 
ion.ucl.ac.uk/spm/). For preprocessing, the initial four time points were removed to allow for signal stabilization and participant adaptation. The images of each subject were then corrected for slice timing, realigned for head motion correction, co-registered to the high-resolution 3D-T1 anatomical images, spatially normalized using DARTEL and smoothed with an 8-mm, full-width, half-maximum (FWHM) Gaussian spatial kernel. The exclusion criteria for head motion were a translation of greater than $2.5 \mathrm{~mm}$ or a rotation of more than $2.5^{\circ}$. Data from two participants were eliminated from the subsequent data analyses.

For the first-level analysis, data from the remaining 20 participants were statistically analyzed using general linear models with SPM8. To examine the neural activity associated with the processing of the three types of solutions, three separate regressors were defined (MET, metaphorical solutions; LIT, literal solutions; PRO-R, problem-restatement solutions). These were time-locked to the onset of the solution presentation of $8 \mathrm{~s}$ and then convoluted using the canonical hemodynamic response function (HRF). A high-pass filter with a cutoff frequency of $1 / 128 \mathrm{~Hz}$ was used to correct for lowfrequency components, and serial correlations were corrected using an autoregressive AR (1) model. Motion realignment parameters also were modeled to account for differences related to head movements.

The resulting contrast images from the first-level analysis were then submitted to a full factorial group analysis of variance (ANOVA) using a random effects model. To determine the neural activity related to the metaphorical solutions, we conducted two analyses: metaphorical versus problemrestatement (MET > PRO-R) and metaphorical versus literal (MET > LIT); to determine neural activation associated with the literal solutions, we performed two additional analyses: literal versus problem-restatement (LIT > PRO-R) and literal versus metaphorical (LIT $>$ MET). We then completed a conjunction analysis using the contrasts of metaphorical versus problem-restatement and metaphorical versus literal [(MET > PRO-R) $\cap($ MET $>$ LIT)] to further clarify the neural network uniquely associated with the metaphorical solutions; a similar conjunction analysis was performed to characterize the neural networks common to metaphorical and literal solutions using the contrasts of metaphorical versus problem-restatement and literal versus problem-restatement [(MET $>$ PRO-R) $\cap$ ( LIT $>$ PRO-R)]. Whole brain search results and small-volume correction (SVC) results were reported in the present study. In previous studies, hippocampus and amygdala often were found in the insight processing, so we were interested specifically in detecting the activations of the two regions. When whole-brain results could not detect them, we would use the method of SVC. SVC (Worsley et al., 1996) is a correction you can apply when your a priori hypothesis do not apply the entire brain but only to certain areas that can be included in a volume. In the present study, for specific regions of interest
(ROIs) of bilateral hippocampus and amygdala, we applied a SVC on these ROIs with an anatomical mask according to the AAL template (Tzourio-Mazoyer et al., 2002) provide by WFU PickAtlas software (Maldjian, Laurienti, Kraft, \& Burdette, 2003). For the whole-brain analysis, the threshold was set at $p<0.001$ (voxel level, uncorrected), $p<0.05$ (cluster level, uncorrected), and 50 continuous voxels. For the SVC analysis, the threshold was set at $p<0.001$ (voxel level, uncorrected), $p<0.05$ (cluster level, FWE corrected).

We conducted two analyses to clarify the relationship between insightfulness experiences and brain activities in amygdala and hippocampus. First, hierarchical linear modeling (HLM) was used to test whether the correlation was statistically significant between insightfulness experience and the activities in hippocampus and amygdala. HLM could simultaneously investigate relationships within and between hierarchical levels of grouped data, thereby making it more efficient at accounting for variance among variables at different levels (Woltman, Feldstain, MacKay, \& Rocchi, 2012). Some researchers have demonstrated that the utility of HLM analysis was critical to fMRI studies, which separate within-participants variance from betweenparticipants factors (Schacht et al., 2011). In the present study, the statistical software package HLM 7.0 (Raudenbush, Bryk, \& Congdon, 2010) was used with different solution types nested within each study participant. The signal values extracted from each ROI were entered as the outcome variable in the two-level HLMs, with solution types (Level 1: MET, LIT, PRO-R) nested within participants (Level 2). The ROIs of bilateral amygdala and hippocampus were defined as spheres with a radius of $0.5 \mathrm{~mm}$ centered on the peak coordinates in the conjunction analysis for $($ MET $>$ PRO-R) $\cap($ MET > LIT). Level 1 parameters (MET, LIT, PRO-R) were dummy-coded. Then, we conducted another different general linear model with SPM8 to test the relationship between insightfulness experiences and the activities in hippocampus and amygdala. We defined high-insight metaphor events (HI-MET, above mean) and low-insight metaphor events (LIMET, below mean) for 16 participants based on their own average score of insightfulness and for 4 participants based on their median (when average score failed in dividing metaphor events into roughly equal HI-MET and LI-MET events), and then compared them in the contrast of high-insight metaphor versus lowinsight metaphor (HI-MEI > LI-MEI). For this analysis, the threshold was set at $p<0.005$ (voxel level, uncorrected).

\section{Results}

\section{Behavioral ratings in the scanning and rating phases}

During the fMRI scanning phase, only the emotional valence of the solutions was assessed. A one-way repeated-measures ANOVA found a significant main effect, $F(2,38)=519.84, p$ 
$<0.001, \eta_{p}^{2}=0.965,90 \% \mathrm{CI}=[0.942,0.973]$ and the adjusted $p<0.001$ (Bonferroni correction for multivariates). A Bonferroni simple effects analysis further showed that there was no significant difference in the emotional valence ratings between the metaphorical and literal solutions (MET: $M=$ 7.27, $S D=0.55$; LIT: $M=7.23, S D=0.45$, respectively) but that they were significantly higher than the problemrestatement solutions (PRO-R: $M=2.98, S D=0.51$; Fig. 2A).

In the rating phase, both the problems and solutions were assessed. For the former, emotional valence and adaptability were rated. One sample $t$-tests for the scores of emotional valence and adaptability indicated that the ratings for emotional valence $(M=2.64, S D=0.65)$ and adaptability $(M=2.88$, $S D=1.19$ ) were both significantly lower than the neutral point of the scales (score of 5 on the 9-point scale), suggesting that the problems represented emotionally negative and maladaptive situations.

For the solutions, insightfulness, novelty, emotional valence, and adaptability were assessed. One-way repeated-measures ANOVAs were performed separately. We found significant main effects of solution type on insightfulness and novelty: for insightfulness, $F(2,38)=66.43, p<0.001, \eta_{p}^{2}=0.778,90 \%$ $\mathrm{CI}=[0.649,0.830]$ and the adjusted $p<0.001$ (Bonferroni correction for multivariates); for novelty, $F(2,38)=51.92, p<$ $0.001, \eta_{p}^{2}=0.732,90 \% \mathrm{CI}=[0.582,0.796]$ and the adjusted $p<$ 0.001 (Bonferroni correction for multivariates). Simple effects analyses for insightfulness and novelty revealed significant differences in the three pairwise comparisons among the metaphorical (insightfulness: $M=6.73, S D=1.04$; novelty, $M=6.59, S D$ =1.15), literal (insightfulness: $M=6.08, S D=1.16$; novelty, $M=$ 5.15, $S D=1.78)$, and problem-restatement solutions (insightfulness: $M=3.29, S D=1.42$; novelty, $M=3.10, S D=$ $1.46), p<0.01$ for each (Bonferroni correction for multiple comparisons) (Fig. 2B1 and B2). We further found significant main effects of solution type on emotional valence and adaptability: for emotional valence, $F(2,38)=311.63, p<0.001, \eta_{p}^{2}=0.943$, $90 \% \mathrm{CI}=[0.906,0.956]$ and the adjusted $p<0.001$ (Bonferroni correction for multivariates); for adaptability, $F(2,38)=118.61$, $p<0.001, \eta_{p}^{2}=0.862,90 \% \mathrm{CI}=[0.778,0.895]$ and the adjusted $p<0.001$ (Bonferroni correction for multivariates). Simple effects analyses indicated that there was no difference in the emotional valence and adaptability between metaphorical (emotional valence: $M=7.12, S D=0.61$; adaptability: $M=6.92, S D=0.76$ ) and literal solutions (emotional valence: $M=6.95, S D=0.54$; adaptability: $M=6.71, S D=0.78)$; the scores in metaphorical and literal solutions were significantly higher than in problemrestatement solutions (emotional valence: $M=2.87, S D=0.74$; adaptability: $M=2.99, S D=1.33), p<0.001$ for each (Bonferroni correction for multiple comparisons) (Fig. 2B3 and B4). It should be noted that we assessed insightfulness, novelty, adaptability, and emotional valence after the fMRI scanning rather than during the fMRI scanning and got similar response patterns to previous study (Yu et al., 2016) [e.g., Insightfulness: present study (MET, $M=6.73$; LIT, $M=6.08 ; M=3.29$ ) vs. previous study for student sample (MET, $M=6.89$; LIT, $M=$ 6.31; PRO-R, $M=3.74)$ ], indicating these ratings in the present study were reliable.

\section{Imaging results}

\section{Neural activations related to the metaphorical and literal solutions}

Concerning the neural activation related to metaphorical solutions, the contrast between MET > PRO-R indicated that many brain areas showed greater activation in response to metaphorical solutions than problem-restatement solutions. These areas included the bilateral inferior frontal gyrus, left superior temporal gyrus, bilateral middle temporal and occipital gyri, bilateral hippocampus, amygdala, fusiform gyrus, left insula, postcentral gyrus, right lingual gyrus, superior occipital gyrus, and the bilateral thalamus. The contrast between MET > LIT revealed a widespread network pattern of brain activity similar to that shown in the contrast between MET > PRO-R (Table 2).
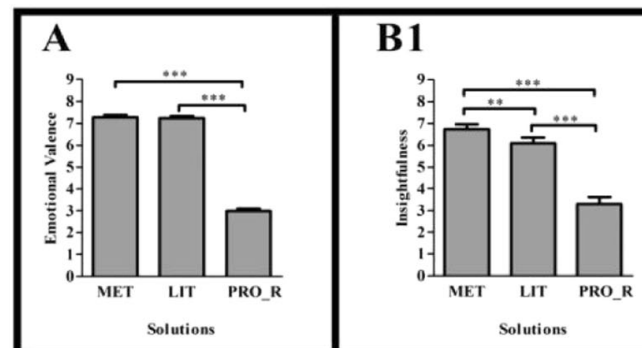

B2

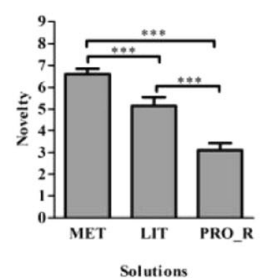

Fig. 2 Behavioral ratings in the scanning and rating phases. (A) Emotional valence ratings of the metaphorical, literal and problemrestatement solutions during the scanning phase. (B1) Insightfulness, (B2) novelty, (B3) emotional valence, and (B4) adaptability ratings of the metaphorical, literal and problem-restatement solutions in the rating phase. There were significant differences on insightfulness and novelty ratings in the pairwise comparisons among metaphorical, literal and problem-restatement solutions. $* * p<0.01$. $* * p<<0.001$. MET $=$ metaphorical; LIT $=$ literal; $\mathrm{PRO}-\mathrm{R}=$ problem-restatement 
For the literal solutions, a contrast between LIT > PRO-R showed increased activation in the left postcentral and precentral gyri, paracentral lobule, superior parietal lobule, insula, cingulate gyrus, right cuneus, parahippocampal gyrus, and bilateral anterior cingulate cortex. The contrast between LIT > MET revealed an enhancement of activity in the left and right precuneus, left superior parietal lobule, medial frontal gyrus, and anterior cingulate cortex. The pattern of brain activity associated with the literal solutions was different from that which was elicited by metaphorical solutions (Table 2 ).

\section{Common activation patterns with conjunction analysis}

Conjunction analyses using MET $>$ PRO-R and MET $>$ LIT contrasts found that a widely distributed network of brain areas was significantly activated in response to metaphorical solutions. These areas included the left inferior frontal gyrus, superior and middle temporal gyri, bilateral hippocampus, amygdala, left fusiform and lingual gyri, and the bilateral middle and inferior occipital gyri (Table 3; Fig. 3).

Conjunction analyses using MET $>$ PRO-R and LIT $>$ PRO$\mathrm{R}$ contrasts found several significant activation clusters, including the left postcentral and precentral gyri, paracentral and superior parietal lobules, cingulate gyrus, insula, thalamus, right cuneus, and parahippocampal gyrus (Table 3; Fig. 4).

\section{Correlations between neural activations and insightfulness}

The results of HLM revealed that, across all the participants, the regression coefficients between insightfulness experiences and the activities of four ROIs were all positive and statistically significant, left amygdala, $\beta=0.276, p<0.001$; right amygdala, $\beta=$ $0.183, p<0.05$; left hippocampus, $\beta=0.343, p<0.001$; right hippocampus, $\beta=0.248, p<0.001$ (Fig. 5A), respectively, indicating significant correlations between insightfulness and the activations of bilateral hippocampus and amygdala.

The contrast between HI-MET > LI-MET (Fig. 5B) found significant activations in the bilateral hippocampus and bilateral amygdala (Hippocampus_L, MNI [7 -12 -36], T uncorrected = 3.05; Hippocampus R, MNI [24 39 -24], $\mathrm{T}_{\text {uncorrected }}=3.93$; Amygdala_L, MNI [ $\left[\begin{array}{lll}-30 & 0 & -18\end{array}\right], \mathrm{T}_{\text {uncorrected }}=2.89$; Amygdala_R, MNI [-36 0 -27], $\left.\mathrm{T}_{\text {uncorrected }}=2.89\right)$ with a loose threshold ( $p<0.005$, voxel level, uncorrected), indicating significant relationship between insightfulness and the activations of bilateral hippocampus and amygdala.

\section{Discussion}

To the best of our knowledge, the present study is the first to examine directly the neural correlates of metaphor in a psychotherapy scenario. Therapeutic metaphor activated two neural networks: one is associated with basic metaphorical language processing, including the IFG, MTG, and STG, and the other is a specific network correlated with insightful problem solving, which includes the hippocampus, amygdala, and fusiform gyrus. These data were compared with activity elicited by literal and problem-restatement solutions.

\section{General neural network involved in basic metaphorical language processing}

Metaphorical solutions activated a basic neural network involved in metaphorical language processing that includes the bilateral IFG, left STG, and MTG. Meta-analyses of neuroimaging studies on metaphorical language (Bohrn et al., 2012; Rapp et al., 2012) found that a predominantly left-lateralized network is important for processing metaphorical or figurative expressions relative to literal expressions within a sentence (Mashal, Faust, Hendler, \& Jung-Beeman, 2009; Rapp et al., 2004) and within a naturally evolving coherent story (Eviatar \& Just, 2006; Nagels et al., 2013). The identified areas included the bilateral IFG, left STG, and MTG, as well as medial prefrontal, superior frontal, parahippocampal regions. Our imaging findings overlapped extensively with these results.

The increase in bilateral IFG activity may reflect higher cognitive demands to integrate nonliteral meanings, as opposed to literal ones, into a sentence context or regulate the meaning selection and evaluation during metaphor comprehension, as it is necessary to decide whether the meaning of a word is intended to be literal or nonliteral (Rapp, Erb, Grodd, Bartels, \& Markert, 2011; Rapp et al., 2012). However, IFG activation also is found in insightful problem solving, such as in chunk decomposition task (Huang et al., 2015) and compound remote-associates task (Kizilirmak et al., 2016). Because such trials require semantic selection to obtain an insightful solution, IFG stimulation may primarily reflect the breaking of mental set and set shift (Shen, Luo, Liu, \& Yuan, 2013).

Concerning the left STG/MTG, these regions are situated in an anatomically key position within the language network; they have numerous connections to other cortical association areas, which were found by the meta-analyses to be activated by nonliteral and literal stimuli (Rapp et al., 2012). The left STG/MTG therefore composes a crucial part of the network for nonliteral meaning comprehension and is considered to be important for coherence analysis and processing of texts (Ferstl, Neumann, Bogler, \& Von Cramon, 2008). Past studies also have observed the activation of the left STG/MTG in a reappraisal condition of emotion regulation (Buhle et al., 2014; Ochsner, Silvers, \& Buhle, 2015). A mechanism of reappraisal may depend on retrieval processes, which search semantic memory for concepts that can be used to reinterpret some part of the current situation (Ochsner et al., 2015; 
Table 2 Brain regions activated in the contrasts of MET $>$ PRO-R, MET $>$ LIT, LIT $>$ PRO-R, and LIT $>$ MET

\begin{tabular}{|c|c|c|c|c|c|c|c|c|c|c|}
\hline \multirow[t]{2}{*}{ Brain areas } & \multirow[t]{2}{*}{ BA } & \multirow[t]{2}{*}{ Cluster size } & \multicolumn{3}{|c|}{ Talairach Coordinates } & \multicolumn{3}{|c|}{ MNI Coordinates } & \multirow[t]{2}{*}{$\mathrm{t}$} & \multirow[t]{2}{*}{ Z } \\
\hline & & & $\mathrm{x}$ & $\mathrm{y}$ & $\mathrm{z}$ & $\mathrm{x}$ & $\mathrm{y}$ & $\mathrm{z}$ & & \\
\hline \multicolumn{11}{|l|}{ MET > PRO-R } \\
\hline Left Postcentral Gyrus & 3 & 5026 & -48 & -18 & 48 & -48 & -21 & 51 & 11.82 & Inf \\
\hline Left Insula & 13 & & -39 & -19 & 23 & -39 & -21 & 24 & 7.72 & 6.36 \\
\hline Left Medial Frontal Gyrus & 6 & & -9 & -12 & 48 & -9 & -15 & 51 & 7.42 & 6.18 \\
\hline Left Amygdala & & & -21 & -9 & -10 & -21 & -9 & -12 & 7.41 & 6.18 \\
\hline Left Fusiform Gyrus & 37 & & -42 & -53 & -7 & -42 & -54 & -12 & 7.03 & 5.94 \\
\hline Left Hippocampus & & & -33 & -9 & -15 & -33 & -9 & -18 & 6.99 & 5.91 \\
\hline Left Inferior Frontal Gyrus & 47 & & -36 & 32 & -9 & -36 & 33 & -9 & 6.95 & 5.89 \\
\hline Left Middle Occipital Gyrus & 37 & & -36 & -67 & 1 & -36 & -69 & -3 & 6.28 & 5.45 \\
\hline Left Middle Temporal Gyrus & 38 & & -48 & 8 & -16 & -48 & 9 & -18 & 6.27 & 5.45 \\
\hline Left Superior Temporal Gyrus & 38 & & -53 & 5 & -8 & -54 & 6 & -9 & 6.19 & 5.39 \\
\hline Left Thalamus & & & -12 & -26 & 1 & -12 & -27 & 0 & 6.07 & 5.31 \\
\hline \#Hippocampus_L & & 117 & -21 & -9 & -10 & -21 & -9 & -12 & 7.41 & 6.18 \\
\hline \#Amygdala_L & & 37 & -21 & -6 & -10 & -21 & -6 & -12 & 7.09 & 5.98 \\
\hline Right Lingual Gyrus & 18 & 2258 & 15 & -73 & 6 & 15 & -75 & 3 & 7.67 & 6.33 \\
\hline Right Fusiform Gyrus & $37 / 20$ & & 39 & -47 & -8 & 39 & -48 & -12 & 6.12 & 5.35 \\
\hline Right Middle Temporal Gyrus & $19 / 22$ & & 45 & -78 & 20 & 45 & -81 & 18 & 6.04 & 5.29 \\
\hline Right Superior Occipital Gyrus & 39 & & 36 & -72 & 26 & 36 & -75 & 24 & 5.79 & 5.11 \\
\hline Right Caudate & & & 36 & -18 & -9 & 36 & -18 & -12 & 5.36 & 4.80 \\
\hline Right Hippocampus & & & 33 & -15 & -12 & 33 & -15 & -15 & 5.29 & 4.75 \\
\hline Right Middle Occipital Gyrus & 19 & & 39 & -84 & 12 & 39 & -87 & 9 & 5.02 & 4.55 \\
\hline Right Thalamus & & & 24 & -29 & 4 & 24 & -30 & 3 & 4.91 & 4.47 \\
\hline Right Inferior Frontal Gyrus & 45 & 50 & 50 & 35 & 1 & 51 & 36 & 3 & 4.24 & 3.93 \\
\hline \#Hippocampus_R & & 128 & 39 & -13 & -17 & 39 & -12 & -21 & 5.99 & 5.25 \\
\hline \#Amygdala_R & & 23 & 33 & -4 & -20 & 33 & -3 & -24 & 4.44 & 4.10 \\
\hline \multicolumn{11}{|l|}{ MET > LIT } \\
\hline Left Inferior Frontal Gyrus & $47 / 45$ & 1796 & -36 & 32 & -9 & -36 & 33 & -9 & 6.51 & 5.61 \\
\hline Left Amygdala & & & -18 & -9 & -10 & -18 & -9 & -12 & 5.86 & 5.17 \\
\hline Left Superior Temporal Gyrus & 38 & & -53 & 5 & -8 & -54 & 6 & -9 & 5.81 & 5.12 \\
\hline Left Lingual Gyrus & 18 & & -30 & -76 & -4 & -30 & -78 & -9 & 5.70 & 5.05 \\
\hline Left Fusiform Gyrus & $37 / 20$ & & -42 & -59 & -7 & -42 & -60 & -12 & 5.66 & 5.02 \\
\hline Left Inferior Occipital Gyrus & 19 & & -36 & -70 & -4 & -36 & -72 & -9 & 5.57 & 4.95 \\
\hline Left Middle Frontal Gyrus & $46 / 8$ & & -53 & 33 & 15 & -54 & 33 & 18 & 5.20 & 4.68 \\
\hline Left Middle Temporal Gyrus & $22 / 38$ & & -59 & -32 & 4 & -60 & -33 & 3 & 5.12 & 4.63 \\
\hline \#Hippocampus_L & & 43 & -18 & -9 & -10 & 33 & -3 & -24 & 5.86 & 5.17 \\
\hline \#Amygdala_L & & 25 & -21 & -2 & -10 & -21 & -2 & -12 & 4.81 & 4.39 \\
\hline Right Sub-Gyra1/Hippocampus & 20 & 81 & 39 & -13 & -20 & 39 & -12 & -24 & 5.12 & 4.63 \\
\hline Right Amygdala & & & 21 & -9 & -10 & 21 & -9 & -12 & 3.44 & 3.27 \\
\hline Right Middle Occipital Gyrus & 18 & 137 & 33 & -84 & 4 & 33 & -87 & 0 & 4.54 & 4.18 \\
\hline \#Hippocampus_R & & 29 & 39 & -13 & -20 & 39 & -12 & -24 & 5.12 & 4.63 \\
\hline \#Amygdala_R & & 3 & 33 & -4 & -20 & 33 & -3 & -24 & 4.57 & 4.20 \\
\hline \multicolumn{11}{|l|}{ LIT $>$ PRO-R } \\
\hline Left Postcentral Gyrus & $3 / 7 / 5$ & 2116 & -48 & -18 & 48 & -48 & -21 & 51 & 8.62 & 6.87 \\
\hline Left Precentral Gyrus & 4 & & -36 & -24 & 48 & -36 & -27 & 51 & 8.37 & 6.73 \\
\hline Left Insula & 13 & & -36 & -16 & 23 & -36 & -18 & 24 & 6.68 & 5.72 \\
\hline Left Cingulate Gyrus & $31 / 24$ & & -9 & -9 & 47 & -9 & -12 & 51 & 6.30 & 5.46 \\
\hline Left Paracentral Lobule & 6 & & -12 & -27 & 48 & -12 & -30 & 51 & 5.07 & 4.59 \\
\hline
\end{tabular}


Table 2 (continued)

\begin{tabular}{|c|c|c|c|c|c|c|c|c|c|c|}
\hline \multirow[t]{2}{*}{ Brain areas } & \multirow[t]{2}{*}{ BA } & \multirow[t]{2}{*}{ Cluster size } & \multicolumn{3}{|c|}{ Talairach Coordinates } & \multicolumn{3}{|c|}{ MNI Coordinates } & \multirow[t]{2}{*}{$\mathrm{t}$} & \multirow[t]{2}{*}{ Z } \\
\hline & & & $\mathrm{x}$ & $\mathrm{y}$ & $\mathrm{z}$ & $\mathrm{x}$ & $\mathrm{y}$ & z & & \\
\hline Left Superior Parietal Lobule & 5 & & -21 & -41 & 57 & -21 & -45 & 60 & 4.97 & 4.51 \\
\hline Right Cuneus & 17 & 506 & 18 & -72 & 9 & 18 & -75 & 6 & 7.23 & 6.07 \\
\hline Right Parahippocampal Gyrus & 19 & & 33 & -47 & -3 & 33 & -48 & -6 & 4.11 & 3.83 \\
\hline Right Anterior Cingulate & 24 & 226 & 6 & 35 & 7 & 6 & 36 & 9 & 5.03 & 4.56 \\
\hline Left Anterior Cingulate & 32 & & -18 & 35 & 7 & -18 & 36 & 9 & 3.94 & 3.69 \\
\hline \multicolumn{11}{|l|}{ LIT > MET } \\
\hline Left Precuneus & $7 / 31$ & 495 & -9 & -68 & 39 & -9 & -72 & 39 & 4.66 & 4.27 \\
\hline Right Precuneus & 7 & & 12 & -60 & 33 & 12 & -63 & 33 & 4.12 & 3.84 \\
\hline Right Superior Parietal Lobule & 7 & & 6 & -64 & 53 & 6 & -69 & 54 & 3.88 & 3.64 \\
\hline Left Middle Frontal Gyrus & $10 / 11$ & 63 & -27 & 49 & -8 & -27 & 51 & -6 & 3.68 & 3.47 \\
\hline Left Anterior Cingulate & 32 & & -21 & 33 & 12 & -21 & 33 & 15 & 3.37 & 3.20 \\
\hline
\end{tabular}

BA, Brodmann area. Only clusters (with local maxima coordinates) up to the thresholds of $p<0.001$ (uncorrected), $p<0.05$ (cluster level, uncorrected) and 50 or more contiguous voxels were reported. \# means Small Volume Correction, clusters up to the thresholds of $p<0.001$ (voxel level, uncorrected) and $p<0.05$ (FWE corrected) were reported. MET = metaphorical; LIT = literal; PRO-R = problem-restatement

Ohlsson, 1984). More importantly, some studies on insight found that insightful events were accompanied with increased activity in the left or right STG using the compound remote associates task (Jung-Beeman et al., 2004; Subramaniam, Kounios, Parrish, \& Jung-Beeman, 2009; Tik et al., 2018). The present study was consistent with these findings. We speculated that the STG was involved in actively semantic retrieval processes, which were required for the insightful problem solving both in the compound remote associates task and in the metaphorical solution to mental distress problem.

\section{Neural network involved in insight processing}

Relative to literal and problem-restatement solutions, we observed greater activation in the bilateral hippocampus, amygdala, and fusiform gyrus. We also observed greater insightfulness and novelty experiences but indiscriminate emotional valence and adaptability experiences. This result was consistent with previous findings (Jiang et al., 2016; Yu et al., 2016). More importantly, we found significant correlations between the insightfulness experiences and the activities in hippocampus and amygdala.

Several investigations have observed the activation of the hippocampus, amygdala, and fusiform gyrus at the moment insight occurs. There is good consistency with previous studies on insight. Using a brain teaser riddle paradigm, Luo and Niki (2003) revealed that the hippocampus and fusiform gyrus were significantly activated by induced insight. The hippocampus and amygdala were found to be activated by induced insight in the interactive effect between novelty and appropriateness using the chunk decomposition paradigm (Huang et al., 2015), with other perceptual paradigms
(Kizilirmak et al., 2016; Ludmer et al., 2011), and with Chinese "chengyu" riddles (Zhao et al., 2013). In addition, activation of the hippocampus was observed following selfgenerated insight via a compound remote associates task (Tik et al., 2018). Moreover, human subjects remember contexts in which they had an "aha" experience better than those in which they failed to feel the "aha" effect (Auble, Franks, \& Soraci, 1979; Jung-Beeman et al., 2004; Wills, Soraci, Chechile, \& Taylor, 2000). Amygdala activity could predict the consolidation of insightful solutions in long-term memory (Kizilirmak et al., 2016; Ludmer et al., 2011). Therapeutic metaphor solution in a psychotherapy scenario produced an obvious insight process similar to previous insight studies and may improve memory, relative to literal solutions.

One reason that therapeutic metaphors promote insight is the novelty of metaphorical expression. Specifically, metaphorical expression enables the person to access a conceptual structure common to an abstract concept of problem and a remote, imaginative concept of metaphorical solution (Landau, Arndt, \& Cameron, 2018), but literal expression does not have this function. Similarly, hippocampus and amygdala activation also has been revealed in novelty detection. It was found that these areas feature higher activity in response to novel stimuli in comparison to common stimuli when using emotional images (Blackford, Buckholtz, Avery, \& Zald, 2010; Weierich, Wright, Negreira, Dickerson, \& Barrett, 2010). The hippocampus and amygdala also respond selectively to conditions containing semantic and perceptual novelty (Hashimoto et al., 2012; Henke, Weber, Kneifel, Wieser, \& Buck, 1999; O'Kane, Insler, \& Wagner, 2005; Poppenk et al., 2008; Stoppel et al., 2009; Strange \& Dolan, 2001; Strange, Fletcher, Henson, Friston, \& Dolan, 1999). In 
Table 3 Conjunction analyses for (MET $>$ PRO-R) $\cap($ MET $>$ LIT) and (MET $>$ PRO-R $) \cap($ LIT $>$ PRO-R)

\begin{tabular}{|c|c|c|c|c|c|c|c|c|c|c|}
\hline \multirow[t]{2}{*}{ Brain areas } & \multirow[t]{2}{*}{ BA } & \multirow[t]{2}{*}{ Cluster size } & \multicolumn{3}{|c|}{ Talairach Coordinates } & \multicolumn{3}{|c|}{ MNI Coordinates } & \multirow[t]{2}{*}{$\mathrm{t}$} & \multirow[t]{2}{*}{ Z } \\
\hline & & & $\mathrm{x}$ & $\mathrm{y}$ & $\mathrm{z}$ & $\mathrm{x}$ & $\mathrm{y}$ & $\mathrm{z}$ & & \\
\hline \multicolumn{11}{|l|}{$($ MET $>$ PRO-R $) \cap($ MET $>$ LIT $)$} \\
\hline Left Inferior Frontal Gyrus & 47 & 951 & -36 & 32 & -9 & -36 & 33 & -9 & 6.51 & 5.61 \\
\hline Left Amygdala & & & -18 & -9 & -10 & -18 & -9 & -12 & 5.86 & 5.17 \\
\hline Left Superior Temporal Gyrus & 38 & & -53 & 5 & -8 & -54 & 6 & -9 & 5.81 & 5.12 \\
\hline Left Fusiform Gyrus & $37 / 20$ & & -42 & -59 & -7 & -42 & -60 & -12 & 5.66 & 5.02 \\
\hline Left Inferior Occipital Gyrus & 19 & & -36 & -70 & -4 & -36 & -72 & -9 & 5.32 & 4.77 \\
\hline Left Middle Temporal Gyrus & $38 / 22$ & & -48 & 8 & -16 & -48 & 9 & -18 & 5.02 & 4.55 \\
\hline Left Lingual Gyrus & 18 & & -24 & -79 & -1 & -24 & -81 & -6 & 4.90 & 4.46 \\
\hline Left Middle Occipital Gyrus & 18 & & -27 & -87 & 4 & -27 & -90 & 0 & 4.34 & 4.02 \\
\hline Left Hippocampus & & & -33 & -9 & -15 & -33 & -9 & -18 & 4.30 & 3.99 \\
\hline \#Hippocampus_L & & 43 & -18 & -9 & -10 & -18 & -9 & -12 & 5.86 & 5.17 \\
\hline \#Amygdala_L & & 25 & -21 & -6 & -10 & -21 & -6 & -12 & 4.81 & 4.39 \\
\hline Right Sub-Gyral/Hippocampus & 20 & 77 & 39 & -13 & -20 & 39 & -12 & -24 & 5.12 & 4.63 \\
\hline Right Amygdala & & & 21 & -9 & -10 & 21 & -9 & -12 & 3.44 & 3.27 \\
\hline Right Middle Occipital Gyrus & 19 & 102 & 36 & -84 & 7 & 36 & -87 & 3 & 4.32 & 4.00 \\
\hline Right Inferior Occipital Gyrus & 19 & & 33 & -73 & 1 & 33 & -75 & -3 & 3.43 & 3.25 \\
\hline \#Hippocampus_R & & 29 & 39 & -13 & -20 & 39 & -12 & -24 & 5.12 & 4.63 \\
\hline \#Amygdala_R & & 3 & 33 & -4 & -20 & 33 & -3 & -24 & 4.44 & 4.10 \\
\hline \multicolumn{11}{|c|}{ (MET > PRO-R ～( LIT > PRO-R) } \\
\hline Left Postcentral Gyrus & $3 / 7$ & 1707 & -48 & -18 & 48 & -48 & -21 & 51 & 8.62 & 6.87 \\
\hline Left Precentral Gyrus & 4 & & -36 & -24 & 48 & -48 & -21 & 51 & 8.37 & 6.73 \\
\hline Left Insula & 13 & & -36 & -16 & 23 & -36 & -18 & 24 & 6.68 & 5.72 \\
\hline Left Cingulate Gyrus & $31 / 24$ & & -9 & -9 & 47 & -9 & -12 & 51 & 6.30 & 5.46 \\
\hline Left Paracentral Lobule & 6 & & -12 & -27 & 48 & -12 & -30 & 51 & 5.07 & 4.59 \\
\hline Left Superior Parietal Lobule & 5 & & -21 & -41 & 57 & -21 & -45 & 60 & 4.97 & 4.51 \\
\hline Left Thalamus & & & -15 & -20 & 4 & -15 & -21 & 3 & 3.72 & 3.51 \\
\hline Right Cuneus & 17 & 471 & 15 & -75 & 9 & 15 & -78 & 6 & 7.14 & 6.01 \\
\hline Right Parahippocampal Gyrus & 19 & & 33 & -47 & -3 & 33 & -48 & -6 & 4.11 & 3.83 \\
\hline
\end{tabular}

BA, Brodmann area. Only clusters (with local maxima coordinates) up to the thresholds of $p<0.001$ (uncorrected), $p<0.05$ (cluster level, uncorrected) and 50 or more contiguous voxels were reported. \# means Small Volume Correction, clusters up to the thresholds of $p<0.001$ (voxel level, uncorrected) and $p<0.05$ (FWE corrected) were reported. MET = metaphorical; LIT = literal; PRO-R = problem-restatement

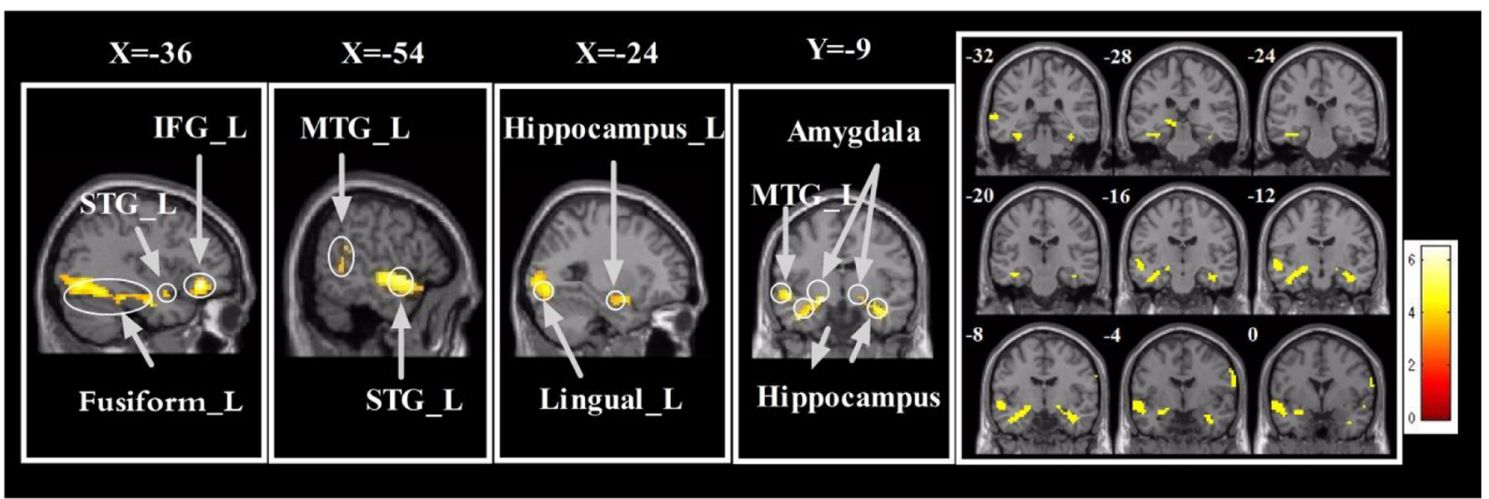

Fig. 3 Conjunction analysis for $($ MET $>$ PRO-R $) \cap($ MET $>$ LIT). Brain regions showed more activation specifically for the metaphorical solutions. MET = metaphorical; LIT = literal; PRO-R = problem-restatement 


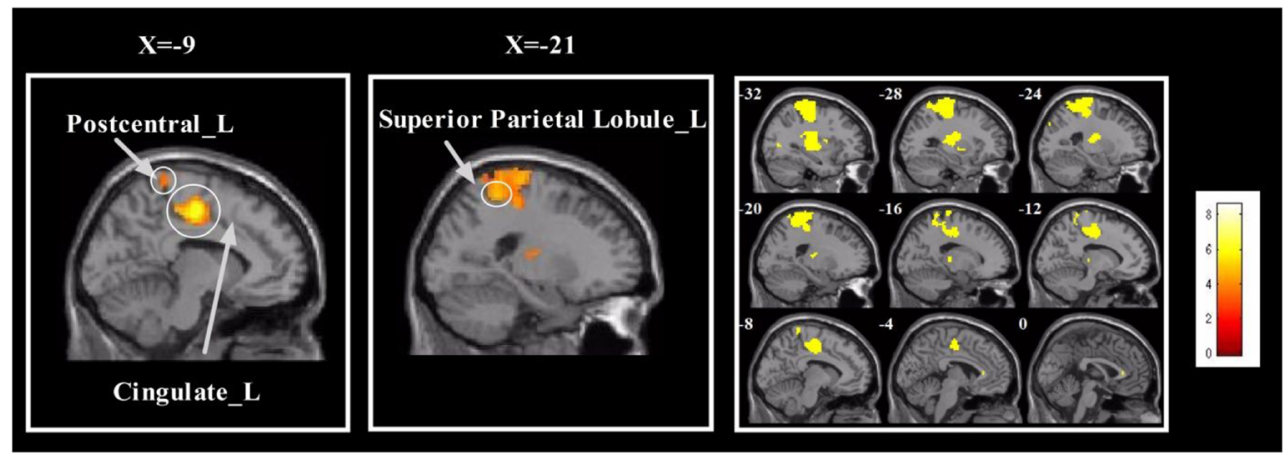

Fig. 4 Conjunction analysis for $($ MET $>$ PRO-R) $\cap$ (LIT $>$ PRO-R). Brain regions common to metaphorical and literal solutions. MET = metaphorical; LIT = literal; PRO-R = problem-restatement

the present study, metaphorical solutions related a novel concept ("playing bad cards well"; see the example in Materials) to an old concept (major) by identifying similarities between them. In contrast, literal expressions did not introduce a new concept: its solution was limited to the old concept (major). Metaphorical solutions thus produced a greater change in cognitive representation than literal solutions; novelty largely accounts for this difference. Ohlsson (1984) suggested that whether a representational change results in a goal state (insight) mainly depends on the distance between the current state and the goal state in the new representation. In this regard, the novelty of metaphorical solutions contributed much to induce insight.

Another reason may be that problem context of mental distress could enhance the effect of metaphorical solution, because problem context increased the practicality of metaphorical solution. First, insightful problem solving is a classic type of creative thinking in which originality (novelty) and practicality (adaptability) are both key factors (Abraham \& Windmann, 2007; Huang et al., 2015; Huang, Tang, Sun, \& Luo, 2018). Huang et al. (2015) used an insight task of chunk decomposition that systematically varied in novelty and appropriateness (practicality) to elucidate their neural mechanisms. The study associated the activations of the hippocampus and amygdala with the interactive effect of novelty and appropriateness, indicating both high novelty and high appropriateness were important to produce insight. The present study replicated their findings in hippocampus and amygdala. Second, the activations of hippocampus and amygdala had been rarely found in the meta-analysis studies on metaphor (Bohrn et al., 2012; Rapp et al., 2012); one reason may be the absence of the context in the metaphorical expression. In contrast, this study first presented a context of mental distress problem and then a metaphorical solution, this created a sufficiently complete conception of the problem and allowed the problem solver to address the problem and then apply schematic knowledge of metaphorical solution to think through the target problem (Keefer \& Landau, 2016). Third, the above discussions revealed a limitation of the present study: it did not manipulate the level of adaptability on insight processing. Metaphorical solutions thus featured high novelty and high adaptability; literal solutions, low novelty, and high adaptability; and problem-restatement solutions, low novelty, and low adaptability. Regardless, we still observed the activations of hippocampus and amygdala in response to metaphorical solutions, which was highly consistent with Huang et al. (2015). Metaphorical solutions therefore meet the requirements of creativity in that they are both novel and adaptive.

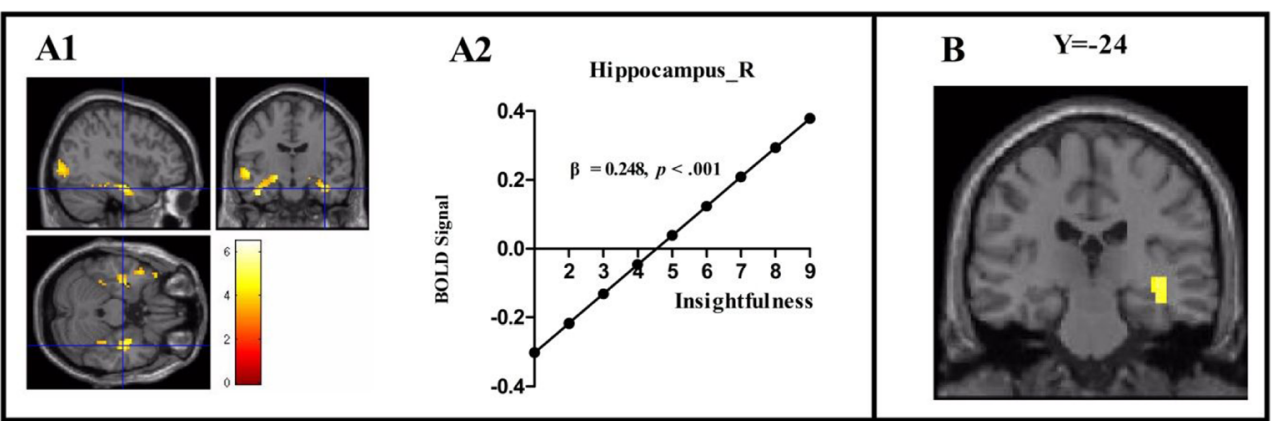

Fig. 5 Correlation analyses between the right hippocampus and insightfulness experience. (A1) The peak coordinates $(39,-12,-24)$ of the right hippocampus activated in the conjunction analyses for (MET > PRO-R) $\cap$ (MET > LIT). (A2) Correlation between insightfulness experience and the BOLD signal in right hippocampus, the line indicates the fitting regression equation. (B) Right hippocampus activation in the contrast of HI-MET > LI-MET. MET = metaphorical; LIT = literal; PRO-R = problem-restatement; HI-MET $=$ high insightful metaphor; LI-MET = low insightful metaphor 
However, future studies should adjust the adaptability of metaphorical and literal solutions to identify corresponding differences in the elicited neural activity.

Regarding the functions of the hippocampus and amygdala, they appeared to work synergistically, but their roles in insightful problem solving were not necessarily the same. Although the hippocampus often is regarded as solely associated with long-term declarative memory, it contributes to creative thinking. For example, Luo and Niki (2003) found that a riddle paradigm elicited activity in the hippocampus, suggesting that the hippocampus participates in insightful problem solving by forming new association and breaking mental fixation. Participants with hippocampal damage performed less well than healthy controls on subcomponents of the Torrance tests of creative thinking (Duff, Kurczek, Rubin, Cohen, \& Tranel, 2013) and on the compound remote associates task (Warren, Kurczek, \& Duff, 2016). Moreover, it was suggested that the relational binding and representational flexibility provided by the hippocampal declarative memory system positions the hippocampus as a key contributor to language use and processing (Duff \& Sarah, 2012). These findings indicate that hippocampal-dependent declarative memory is necessary for creative problem solving. By comparison, the amygdala has been demonstrated to involve enhancing the processing of emotionally arousing stimuli and modulating enhanced memory consolidation with the hippocampus (Girardeau, Inema, \& Buzsáki, 2017; Yang \& Wang, 2017). Thus, metaphorical solutions containing creative and emotional information would activate both the hippocampus and amygdala, as well as promote long-term memory to yield an effective therapeutic impact.

In addition, we observed that the presentation of metaphorical solutions activated the right lingual and occipital gyri. However, this region has received scant attention in past research. As increased activity in the lingual gyrus has been observed using an insight task with heuristic prototypes, it has been suggested that it might be involved in forming novel associations using heuristic information (Luo et al., 2013).

\section{Common neural network involving insightful and non-insightful processing}

A shared neural network may be involved in the processing of metaphorical and literal solutions, as opposed to that which underlies problem-restatement solutions. The left cingulate cortex is primarily recruited in task-related goal directing and governing, the superior parietal lobule and cuneus may in reorientation or visual-spatial information processing, and the left insula in emotional valence (Shen et al., 2013). The left postcentral and precentral gyri may reflect semantic processing associated with sensory and motor components (Rapp et al., 2012). All of these regions may contribute to a general cognitive process that may or may not lead to insight.

\section{Conclusions, implications, and limitations}

The present study explored whether metaphorical solutions to mental distress problems would yield a salient insight process and activate a neural network similar to that which underlies insightful problem solving. To compile experimental stimuli, we designed text-based micro-counseling dialogue scenarios that reflected psychotherapy; they resembled real-life situations and therefore featured high ecological validity in eliciting the insight process. The results revealed that metaphorical solutions in a psychotherapy context activated a neural network that included the hippocampus and amygdala; this system overlaps extensively with the network of insightful problem solving. These findings have important implications. This study found that therapeutic metaphor in the problemsolution scenario could produce higher insightfulness, and there were significant correlations between insightfulness experience and activations of hippocampus and amygdala. This implied that therapeutic metaphor got a strong semantic encoding and then could have potential in maintaining a longer time and producing a better intervention effect. This effect may be a lie in that metaphorical solutions could trigger a creative cognitive process by activating widely separated areas of long-term memory and combining normally unassociated concepts. Therefore, the use of therapeutic metaphor should be emphasized in the psychotherapy.

There are some limitations in the presented study. First, to obtain both detailed information of subjective experiences and high quality of fMRI data, we let participants assess materials after the fMRI scanning rather than make real-time ratings during the fMRI scanning. The ratings obtained from the second reading may have some differences from the first reading due to the changes of familiarity, so it should be cautious to understand their correlative analysis with neural activities. Second, the same metaphor might have a different impact on the individuals from different cultural background due to the limitation of cultural appropriateness. For instance, in the example of college major, in America, it could be a good idea to offer help in dealing with either frustration or choosing a major that one likes. But in China, due to the specific enrollment system, some Chinese college students are not matriculated by the majors they declare and are transferred to other majors they do not like so much. The present study focused on offering help in realizing the future may not only depend on what you have but on what you do.

Acknowledgements This research was supported by the National Natural Science Foundation of China [grant numbers 31371131, 31100746) and the Major Projects of the Beijing Municipal Science and Technology Commission (grant number D151100002315003). The authors have no conflicts of interest to declare.

Publisher's note Springer Nature remains neutral with regard to jurisdictional claims in published maps and institutional affiliations. 


\section{References}

Abraham, A., \& Windmann, S. (2007). Creative cognition: The diverse operations and the prospect of applying a cognitive neuroscience perspective. Methods, 42(1), 38-48. doi:https://doi.org/10.1016/j. ymeth.2006.12.007

Auble, P. M., Franks, J. J., \& Soraci, S. A. (1979). Effort toward comprehension: Elaboration or "ahap"? Memory \& Cognition, 7(6), 426434.

Barlow, J. M., Pollio, H. R., \& Fine, H. J. (1977). Insight and figurative language in psychotherapy. Psychotherapy Theory Research \& Practice, 14(3), 212-222. doi:https://doi.org/10.1037/h0086530

Benedek, M., Beaty, R., Jauk, E., Koschutnig, K., Fink, A., Silvia, P. J., ... Neubauer, A. C. (2014). Creating metaphors: The neural basis of figurative language production. Neuroimage, 90, 99-106. doi: https://doi.org/10.1016/j.neuroimage.2013.12.04

Blackford, J. U., Buckholtz, J. W., Avery, S. N., \& Zald, D. H. (2010). A unique role for the human amygdala in novelty detection. Neuroimage, 50(3), 1188-1193. doi:https://doi.org/10.1016/j. neuroimage.2009.12.083

Bohrn, I. C., Altmann, U., \& Jacobs, A. M. (2012). Looking at the brains behind figurative language - A quantitative meta-analysis of neuroimaging studies on metaphor, idiom, and irony processing. Neuropsychologia, 50(11), 2669-2683. doi:https://doi.org/10.1016/ j.neuropsychologia.2012.07.021

Buhle, J. T., Silvers, J. A., Wager, T. D., Lopez, R., Onyemekwu, C., Kober, H., ... Ochsner, K. N. (2014). Cognitive reappraisal of emotion: A meta-analysis of human neuroimaging studies. Cerebral Cortex, 24(11), 2981-2990. doi:https://doi.org/10.1093/cercor/ bht154

Duff, M. C., Kurczek, J., Rubin, R., Cohen, N. J., \& Tranel, D. (2013). Hippocampal amnesia disrupts creative thinking. Hippocampus, 23(12), 1143-1149. doi:https://doi.org/10.1002/hipo.22208

Duff, M. C., \& Sarah, B. S. (2012). The hippocampus and the flexible use and processing of language. Frontiers in Human Neuroscience, 6(10), 69. doi:https://doi.org/10.3389/fnhum.2012.00069

Elliott, R., Shapiro, D. A., Firth-Cozens, J., Stiles, W. B., Hardy, G. E., Llewelyn, S. P., \& Margison, F. R. (1994). Comprehensive Process Analysis of Insight Events in Cognitive-Behavioral and Psychodynamic-Interpersonal Psychotherapies. Journal of Counseling Psychology, 41(4), 449-463.

Eviatar, Z., \& Just, M. A. (2006). Brain correlates of discourse processing: An fMRI investigation of irony and conventional metaphor comprehension. Neuropsychologia, 44(12), 2348-2359. doi:https:// doi.org/10.1016/j.neuropsychologia.2006.05.007

Ferstl, E. C., Neumann, J., Bogler, C., \& Von Cramon, D. Y. (2008). The extended language network: A meta-analysis of neuroimaging studies on text comprehension. Human Brain Mapping, 29(5), 581-593. doi:https://doi.org/10.1002/hbm.20422

Gallagher, L., Mcauley, J., \& Moseley, G. L. (2013). A randomizedcontrolled trial of using a book of metaphors to reconceptualize pain and decrease catastrophizing in people with chronic pain. Clinical Journal of Pain, 29(1), 20-25.

Girardeau, G., Inema, I., \& Buzsáki, G. (2017). Reactivations of emotional memory in the hippocampus-amygdala system during sleep. Nature Neuroscience. doi:https://doi.org/10.1038/nn.4637

Grosse Holtforth, M., Castonguay, L. G., Boswell, J. F., Wilson, L. A., Kakouros, A. A., \& Borkovec, T. D. (2007). Insight in CognitiveBehavioral Therapy. 24(13), 57-80.

Hashimoto, R., Abe, N., Ueno, A., Fujii, T., Takahashi, S., \& Mori, E. (2012). Changing criteria for old/new recognition judgments can modulate activity in the anterior hippocampus. Hippocampus, 22(2), 141-148. doi:https://doi.org/10.1002/hipo.20878

Henke, K., Weber, B., Kneifel, S., Wieser, H. G., \& Buck, A. (1999). Human hippocampus associates information in memory.
Proceedings of the National Academy of Sciences, 96(10), 58845889. doi:https://doi.org/10.1073/pnas.96.10.5884

Hu, J., Zhang, W., Zhang, J., Yu, F., \& Zhang, X. (2018). The Brief Intervention Effect of Metaphorical Cognitive Restructuring on Alleviating Mental Distress: A Randomised Controlled Experiment. Applied Psychology: Health and Well-Being, 10(3), 414-433. doi: https://doi.org/10.1111/aphw.12133

Huang, F., Fan, J., \& Luo, J. (2015). The neural basis of novelty and appropriateness in processing of creative chunk decomposition. Neuroimage, 113, 122-132. doi:https://doi.org/10.1016/j. neuroimage.2015.03.030

Huang, F., Tang, S., Sun, P., \& Luo, J. (2018). Neural correlates of novelty and appropriateness processing in externally induced constraint relaxation. Neuroimage, 172, 381-389. doi: https://doi.org/10.1016/ j.neuroimage.2018.01.070

Jiang, N., Yu, F., Zhang, W., \& Zhang, J. (2016). Deficits of cognitive restructuring in major depressive disorder: Measured by textual micro-counseling dialogues. Psychiatry Research, 238, 159-164. doi:https://doi.org/10.1016/j.psychres.2016.02.027

Jung-Beeman, M., Bowden, E. M., Haberman, J., Frymiare, J. L., Arambelliu, S., Greenblatt, R., ... Kounios, J. (2004). Neural activity when people solve verbal problems with insight. Plos Biology, 2(4), 2-4. doi:https://doi.org/10.1371/journal.pbio.0020097

Keefer, L. A., \& Landau, M. J. (2016). Metaphor and analogy in everyday problem solving. Wiley Interdisciplinary Reviews: Cognitive Science, 7(6), 394-405. doi: https://doi.org/10.1002/wcs.1407

Kizilirmak, J. M., Thuerich, H., Folta-Schoofs, K., Schott, B. H., \& Richardson-Klavehn, A. (2016). Neural Correlates of Learning from Induced Insight: A Case for Reward-Based Episodic Encoding. Frontiers in Psychology, 7(1408). doi:https://doi.org/10.3389/ fpsyg.2016.01693

Kok, J. K., Lim, M. C., \& Low, S. K. (2011). Attending to Metaphor in Counselling. International Proceedings of Economics Development \& Research.

Komasi, S., Saeidi, M., Zakiei, A., Amiri, M. M., \& Soltani, B. (2016). Cognitive Restructuring Based on Metaphor Therapy to Combat the Irrational Beliefs of Drug Addicts Undergoing Buprenorphine Treatment. In Press(In Press).

Lakoff, G., \& Johnson, M. (1980). Metaphors We Live By: University Of Chicago Press.

Landau, M. J., Arndt, J., \& Cameron, L. D. (2018). Do metaphors in health messages work? Exploring emotional and cognitive factors. Journal of Experimental Social Psychology, 74, 135-149. doi: https://doi.org/10.1016/j.jesp.2017.09.006

Ludmer, R., Dudai, Y., \& Rubin, N. (2011). Uncovering camouflage: Amygdala activation predicts long-term memory of induced perceptual insight. Neuron, 69(5), 1002-1014. doi:https://doi.org/10.1016/ j.neuron.2011.02.013

Luo, J., Li, W., Jiang, Q., Wei, D., Liu, Y., \& Zhang, Q. (2013). Neural Basis of Scientific Innovation Induced by Heuristic Prototype. Plos One, 8(1), e49231. doi:https://doi.org/10.1371/journal.pone. 0049231

Luo, J., \& Niki, K. (2003). Function of hippocampus in "insight" of problem solving. Hippocampus, 13(3), 316-323.

Mac Cormac, E. R. (1985). A Cognitive Theory of Metaphor: Cambridge, Mass. MIT Press.

Maldjian, J. A., Laurienti, P. J., Kraft, R. A., \& Burdette, J. H. (2003). An automated method for neuroanatomic and cytoarchitectonic atlasbased interrogation of fMRI data sets. Neuroimage, 19(3), 12331239. doi: https://doi.org/10.1016/S1053-8119(03)00169-1

Martin, J., Cummings, A. L., \& Hallberg, E. T. (1992). Therapists' intentional use of metaphor: Memorability, clinical impact, and possible epistemic/motivational functions. Journal of Consulting \& Clinical Psychology, 60(1), 143-145. doi:https://doi.org/10.1037/0022006X.60.1.143 
Mashal, N., Faust, M., Hendler, T., \& Jung-Beeman, M. (2009). An fMRI study of processing novel metaphoric sentences. Laterality, 14(1), $30-54$

Muran, J. C., \& Digiuseppe, R. A. (1990). Towards a cognitive formulation of metaphor use in psychotherapy. Clinical Psychology Review, 10(1), 69-85. doi:https://doi.org/10.1080/13576500802049433

Nagels, A., Kauschke, C., Schrauf, J., Whitney, C., Straube, B., \& Kircher, T. (2013). Neural substrates of figurative language during natural speech perception: An fMRI study. Frontiers in Behavioral Neuroscience, 7(10), 121-121. doi:https://doi.org/10.3389/fnbeh. 2013.00121

Novotney, A. (2013). The therapist effect. Monitor on Psychology, 44(2), 48.

Ochsner, K. N., Silvers, J. A., \& Buhle, J. T. (2015). Functional imaging studies of emotion regulation: A synthetic review and evolving model of the cognitive control of emotion. Annals of the New York Academy of Sciences, 1251(1), E1-E24. doi:https://doi.org/ 10.1111/j.1749-6632.2012.06751.x

Ohlsson, S. (1984). Restructuring revisited : II. An information processing theory of restructuring and insight. Scandinavian Journal of Psychology, 25(2), 117-129.

O'Kane, G., Insler, R. Z., \& Wagner, A. D. (2005). Conceptual and perceptual novelty effects in human medial temporal cortex. Hippocampus, 15(3), 326-332. doi:https://doi.org/10.1002/hipo. 20053

Paivio, A. (1986). Psychological Processes in the Comprehension of Metaphor. Metophor \& Thought, 163.

Pollio, H. R., Barlow, J. M., Fine, H. J., \& Pollio, M. R. (1977). Psychology and the Poetics of Growth: Figurative Language in Psychology, Psychotherapy, and Education. Hillsdale: Erlbaum.

Poppenk, J., Walia, G., Mcintosh, A. R., Joanisse, M. F., Klein, D., \& Köhler, S. (2008). Why is the meaning of a sentence better remembered than its form? An fMRI study on the role of novelty-encoding processes. Hippocampus, 18(9), 909-918. doi:https://doi.org/10. 1002/hipo.20453

Rapp, A. M., Erb, M., Grodd, W., Bartels, M., \& Markert, K. (2011). Neural correlates of metonymy resolution. Brain \& Language, 119(3), 196-205. doi:https://doi.org/10.1016/j.bandl.2011.07.004

Rapp, A. M., Leube, D. T., Erb, M., Grodd, W., \& Kircher, T. T. J. (2004). Neural correlates of metaphor processing. Brain Research Cognitive Brain Research, 20(3), 395-402. doi:https://doi.org/10.1016/j. cogbrainres.2004.03.017

Rapp, A. M., Mutschler, D. E., \& Erb, M. (2012). Where in the brain is nonliteral language? A coordinate-based meta-analysis of functional magnetic resonance imaging studies. Neuroimage, 63(1), 600-610. doi:https://doi.org/10.1016/j.neuroimage.2012.06.022

Stephen Raudenbush, Tony Bryk, \& Congdon, R. (2010). HLM 7 Hierarchical Linear and Nonlinear Modeling (Version 7.0): Scientific Software International, Inc.

Schacht, J. P., Anton, R. F., Randall, P. K., Li, X., Henderson, S., \& Myrick, H. (2011). Stability of fMRI striatal response to alcohol cues: A hierarchical linear modeling approach. Neuroimage, 56(1), 61-68. doi: https://doi.org/10.1016/j.neuroimage.2011.02.004

Shen, W., Luo, J., Liu, C., \& Yuan, Y. (2013). New advances in the neural correlates of insight: A decade in review of the insightful brain. Chinese Science Bulletin, 58(13), 1497-1511.

Slepian, M. L., Weisbuch, M., Rutchick, A. M., Newman, L. S., \& Ambady, N. (2010). Shedding light on insight: Priming bright ideas. Journal of Experimental Social Psychology, 46(4), 696-700. doi: https://doi.org/10.1016/j.jesp.2010.03.009

Stoppel, C. M., Boehler, C. N., Strumpf, H., Heinze, H. J., Hopf, J. M., Düzel, E., \& Schoenfeld, M. A. (2009). Neural correlates of exemplar novelty processing under different spatial attention conditions. Human Brain Mapping, 30(11), 3759-3771. doi:https://doi.org/10. 1002/hbm.20804
Strange, B. A., \& Dolan, R. J. (2001). Adaptive anterior hippocampal responses to oddball stimuli. Hippocampus, 11(6), 690-698. doi: https://doi.org/10.1002/hipo.1084

Strange, B. A., Fletcher, P. C., Henson, R. N., Friston, K. J., \& Dolan, R. J. (1999). Segregating the functions of human hippocampus. Proceedings of the National Academy of Sciences, 96(7), 40344039. doi:https://doi.org/10.1073/pnas.96.7.4034

Subramaniam, K., Kounios, J., Parrish, T. B., \& Jung-Beeman, M. (2009). A brain mechanism for facilitation of insight by positive affect. Journal of Cognitive Neuroscience, 21(3), 415-432. doi: https://doi.org/10.1162/jocn.2009.21057

Tik, M., Sladky, R., Luft, C. D. B., Willinger, D., Hoffmann, A., Banissy, M. J., ... Windischberger, C. (2018). Ultra-high-field fMRI insights on insight: Neural correlates of the Aha!-moment. Human Brain Mapping, 39(8), 3241-3252. doi: https://doi.org/10.1002/hbm. 24073

Tzourio-Mazoyer, N., Landeau, B., Papathanassiou, D., Crivello, F., Etard, O., Delcroix, N., ... Joliot, M. (2002). Automated Anatomical Labeling of Activations in SPM Using a Macroscopic Anatomical Parcellation of the MNI MRI Single-Subject Brain. Neuroimage, 15(1), 273-289. doi: https://doi.org/10.1006/nimg. 2001.0978

Warren, D. E., Kurczek, J., \& Duff, M. C. (2016). What relates newspaper, definite, and clothing? An article describing deficits in convergent problem solving and creativity following hippocampal damage. Hippocampus, 26(7), 835-840.

Weierich, M. R., Wright, C. I., Negreira, A., Dickerson, B. C., \& Barrett, L. F. (2010). Novelty as a dimension in the affective brain. Neuroimage, 49(3), 2871-2878. doi:https://doi.org/10.1016/j. neuroimage.2009.09.047

Wills, T. W., Soraci, S. A., Chechile, R. A., \& Taylor, H. A. (2000). "Aha" effects in the generation of pictures. Memory \& Cognition, 28(6), 939-948.

Woltman, H., Feldstain, A., MacKay, J. C., \& Rocchi, M. (2012). An introduction to hierarchical linear modeling. Tutorials in Quantitative Methods for Psychology, 8(1), 52-69. doi: https://doi. org/10.20982/tqmp.08.1.p052

Worsley, K. J., Marrett, S., Neelin, P., Vandal, A. C., Friston, K. J., \& Evans, A. C. (1996). A unified statistical approach for determining significant signals in images of cerebral activation. Human Brain Mapping, 4(1), 58-73. doi: https://doi.org/10.1002/(SICI)10970193(1996)4:1<58::AID-HBM4>3.0.CO;2-O

Yang, J. (2014). The role of the right hemisphere in metaphor comprehension: A meta-analysis of functional magnetic resonance imaging studies. Human Brain Mapping, 35(1), 107-122. doi:https://doi.org/ $10.1002 / \mathrm{hbm} .22160$

Yang, W., Dietrich, A., Liu, P., Ming, D., Jin, Y., Nusbaum, H. C., ... Zhang, Q. (2016). Prototypes are Key Heuristic Information in Insight Problem Solving. Creativity Research Journal, 28(1), 6777. doi: https://doi.org/10.1080/10400419.2016.1125274

Yang, Y., \& Wang, J. Z. (2017). From Structure to Behavior in Basolateral Amygdala-Hippocampus Circuits. Frontiers in Neural Circuits, 11. doi:https://doi.org/10.3389/fncir.2017.00086

Yu, F., Zhang, W., Zhang, Z., Zhang, J., \& Luo, J. (2016). Insights triggered by textual micro-counseling dialogues of restructuring orientation in experts and students. Psych J, 5(1), 57-68. doi:https://doi. org/10.1002/pchj.104

Zhao, Q., Zhou, Z., Xu, H., Chen, S., Xu, F., Fan, W., \& Han, L. (2013). Dynamic neural network of insight: A functional magnetic resonance imaging study on solving Chinese 'chengyu' riddles. Plos One, 8(3), e59351. doi:https://doi.org/10.1371/journal.pone. 0059351 